\title{
Properties of Rapid Hardening Controlled Low Strength Material Made of Recycled Fine Aggregate from Urban Red Brick Construction Waste
}

\author{
Jin Ran ${ }^{1,2}$, Jinxi Zhang1 \\ ${ }^{1}$ Beijing Key Laboratory of Traffic Engineering, Beijing University of Technology, Beijing, China \\ ${ }^{2}$ Key Laboratory of Expressway Maintenance Technology of Ministry of Transport (Jinan), Jinan, China \\ Email: ranjin@emails.bjut.edu.cn, ranjin1978@hotmail.com
}

How to cite this paper: Ran, J. and Zhang, J.X. (2017) Properties of Rapid Hardening Controlled Low Strength Material Made of Recycled Fine Aggregate from Urban Red Brick Construction Waste. World Journal of Engineering and Technology, 5, 188-197. https://doi.org/10.4236/wjet.2017.52015

Received: March 6, 2017

Accepted: May 7, 2017

Published: May 10, 2017

Copyright $\odot 2017$ by authors and Scientific Research Publishing Inc. This work is licensed under the Creative Commons Attribution International License (CC BY 4.0).

http://creativecommons.org/licenses/by/4.0/

\begin{abstract}
In some cases of emergency backfill engineering projects, traditional backfill materials cannot meet the requirements of fast construction due to their long curing time. This study presents a new kind of rapid hardening controlled low strength material, which utilizes both rapid hardening sulphoaluminate cement and recycled fine aggregate from urban red brick construction waste. Totally, sixteen mixtures were prepared for the experiment with different cement-to-sand ratios and water-to-solid ratios. The flowability and bleeding rate of fresh mixture were measured to evaluate its workability, and the compressive strength of hardened mixture was tested to evaluate its rapid hardening and mechanical properties. Test results indicate that rapid hardening controlled low strength material containing recycled fine aggregate from urban red brick construction waste can achieve the desirable flowability, but the bleeding rate increases with the increase of flowability. In addition, 2-hour compressive strength can reach $0.08-0.12 \mathrm{MPa}$, and 4-hour compressive strength is $0.32-1.54 \mathrm{MPa}$, which can meet the requirements of emergency backfill construction. At last, based on the derived compressive strength, a fitting model for predicting compressive strength evolution of this new rapid hardening backfill material is developed, which fits accurately with these experimental data.
\end{abstract}

\section{Keywords}

Controlled Low Strength Material, Rapid Hardening Sulphoaluminate

Cement, Recycled Fine Aggregate, Construction Waste, Urban Red Brick, Workability, Compressive Strength 


\section{Introduction}

Chinese urban construction waste generally has a high content of waste concrete, waste mortar, waste red clay brick and tiles, waste soil, also the dust and other impurities. At present, its recycling in China is lower due to the difficulty in classification of construction waste and poor quality, which is huge waste of resources. Over the past several decades, a significant research effort has begun aiming at the re-use of construction waste in civil engineering field, e.g. to produce recycled concrete [1], recycled mortar [2]. As for recycled fine aggregate containing red brick debris, which grain size is less than $4.75 \mathrm{~mm}$, currently mainly used to produce some building products such as recycled brick [3], recycled block [4] etc. However, it is too difficult to use on road engineering due to its poor quality.

On the other hand, sudden road subsidence occurs frequently in many cities of China, how to backfill the place of road subsidence quickly has been a serious problem for road management department. Moreover, in urban road construction and maintenance, the construction time limit is very urgent for reducing the effect on the surrounding residents' life. Especially for some backfill projects, such as the pipe trench and the surrounding of inspection well etc., always need to be backfilled rapidly. However, the present traditional backfill materials, such as cement stabilized soil, graded gravel and lime-fly ash stabilized aggregate etc., cannot meet the requirements of fast construction due to their long curing period. Meanwhile, the traditional backfill materials cannot be compacted effectively due to the narrow backfill space or the limitation of pipeline and other structures, which often results in some engineering damages [5].

Controlled low strength material (CLSM), also known as "flowable fill", is employed as a self-compacting cementitious material used as a replacement for compacted back fill. CLSM usually have a specified 28-day compressive strength of $8.3 \mathrm{MPa}$ or less [6]. Compared with conventional backfill materials that require controlled compaction in layers, CLSM has several inherent advantages for use in construction, including: ease of mixing and placement, ability to flow into hard-to-reach places, self-leveling characteristics, rapid curing, incompressibility after curing, which also reduces equipment needs, labor costs, and associated inspections [7] etc. Therefore, CLSM has been popularly used in the construction industry, such as around buried pipes [8], bedding or pavement applications [9] etc.

This paper presents a new kind of rapid hardening controlled low strength material, in which rapid hardening sulphoaluminate cement is used as a binder to achieve the fast-setting and rapid hardening properties. Meanwhile, recycled fine aggregate from urban red brick construction waste is used as natural sand substitute in order to overcome the shortage of natural resources. The objective of this research is to investigate and evaluate the properties of this new backfill material. In additional to that, an attempt to establish an analytical model for predicting its compressive strength is conducted. 


\section{Raw Materials and Experimental Program}

\subsection{Raw Materials}

Rapid hardening sulphoaluminate cement was sampled from Tangshan polar bear building materials Co., Ltd. in Hebei province, China. Its specific surface area is over $350 \mathrm{~m}^{2} / \mathrm{kg}$, the initial setting time is longer than $25 \mathrm{~min}$ and the final setting time is shorter than $180 \mathrm{~min}$. The 1-day, 3-day and 28-day compressive strength of cement are $30.0 \mathrm{MPa}, 42.5 \mathrm{MPa}$ and $45.0 \mathrm{MPa}$, respectively. Its chemical composition is shown in Table 1.

According to Chinese standard "Fly ash used for cement and concrete" (GB/T 1596-2005), the total amounts of $\mathrm{SiO}_{2}, \mathrm{Al}_{2} \mathrm{O}_{3}$ and $\mathrm{Fe}_{2} \mathrm{O}_{3}$ in fly ash is over $70 \%$ and the loss on ignition (LOI) is less than $15 \%$, and the residue on a $45 \mu \mathrm{m}$ sieve is less than $45 \%$ and the water demand ratio is less than $115 \%$. The used chemical admixture is melamine water reducing agent provided by Athanasy technology Co., Ltd. in Beijing, China. The mixing water is tap water.

Recycled fine aggregate from urban red brick construction waste was sampled from a construction waste disposal plant in Beijing. Its chemical composition is shown in Table 2. XRD data are presented in Figure 1, which shows that the majority of crystalline phases present are Quartz $\left[\mathrm{SiO}_{2}\right]$, Calcite $\left[\mathrm{CaCO}_{3}\right]$ and Margarite-2M1 $\left[\mathrm{CaAl}_{2}\left(\mathrm{Si}_{2} \mathrm{Al}_{2}\right) \mathrm{O}_{10}(\mathrm{OH})_{2}\right]$.

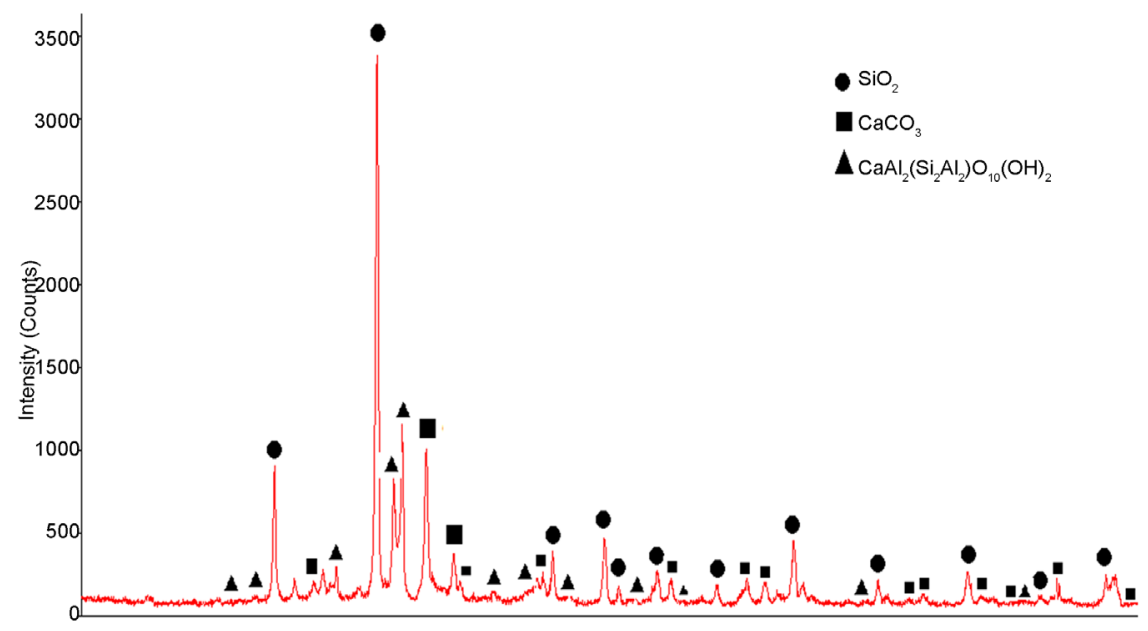

Figure 1. XRD pattern of recycled fine aggregate from urban red brick construction waste.

Table 1. Chemical composition of rapid hardening sulphoaluminate cement/\%.

\begin{tabular}{cccccccccc}
\hline $\mathrm{CaO}$ & $\mathrm{SiO}_{2}$ & $\mathrm{Al}_{2} \mathrm{O}_{3}$ & $\mathrm{MgO}$ & $\mathrm{SO}_{3}$ & $\mathrm{Fe}_{2} \mathrm{O}_{3}$ & $\mathrm{~K}_{2} \mathrm{O}$ & $\mathrm{TiO}_{2}$ & SrO & Others \\
\hline 47.57 & 11.23 & 20.27 & 2.90 & 14.45 & 1.84 & 0.50 & 0.86 & 0.14 & 0.24 \\
\hline
\end{tabular}

Table 2. Chemical composition of recycled fine aggregate from urban red brick construction waste/\%.

\begin{tabular}{cccccccccccc}
\hline $\mathrm{CaO}$ & $\mathrm{SiO}_{2}$ & $\mathrm{Al}_{2} \mathrm{O}_{3}$ & $\mathrm{MgO}$ & $\mathrm{SO}_{3}$ & $\mathrm{Fe}_{2} \mathrm{O}_{3}$ & $\mathrm{~K}_{2} \mathrm{O}$ & $\mathrm{TiO}_{2}$ & $\mathrm{Na}_{2} \mathrm{O}$ & $\mathrm{P}_{2} \mathrm{O}_{5}$ & $\mathrm{M}_{n} \mathrm{O}$ & Others \\
\hline 20.45 & 50.68 & 13.72 & 3.86 & 0.77 & 5.77 & 2.29 & 0.80 & 1.14 & 0.21 & 0.14 & 0.17 \\
\hline
\end{tabular}




\subsection{Mix Proportion}

Sixteen rapid hardening CLSMs were prepared for experiment. Only two mix proportion design parameters are presented in this paper, one is cement-to-sand $(\mathrm{C} / \mathrm{Sa})$ ratio, and the other is water-to-solid (W/So) ratio. The former signifies the weight percentage of cement to recycled fine aggregate, and the latter is the weight percentage of water to the total solid materials used, including recycled fine aggregate, cement, and fly ash. The reasonable weight amounts of fly ash and water reducing agent in each mixture were $15.0 \%$ of recycled fine aggregate, and $3.0 \%$ of cement, respectively, based on several trial tests [10]. The cementto-sand $(\mathrm{C} / \mathrm{Sa})$ ratios were $0.05,0.10,0.15$ and 0.20 , and the water-to-solid (W/So) ratios were $0.25,0.27,0.29$ and 0.31 .

\subsection{Test Procedures}

Before test, recycled fine aggregate from urban red brick construction waste was dried in an oven at $105^{\circ} \mathrm{C} \pm 5^{\circ} \mathrm{C}$ until no further weight reduction. The specimen of rapid hardening CLSM was prepared as follows. Firstly, recycled fine aggregate, rapid hardening sulphoaluminate cement, fly ash and solid melamine water reducing agent were added to the mixer together and dry-mixed for $1 \mathrm{~min}$ or so to ensure the homogeneity of mixture. Then the mixture was mixed with water for additional $3 \mathrm{~min}$. Finally, the fresh mixture produced was poured into the different molds for different tests without compaction or vibration due to its high flow ability.

Flowability test was conducted according to USA standard "Standard Test Method for Flow Consistency of Controlled Low Strength Material (CLSM)" (ASTM D6103-04). The cylinder mold $(76 \times 150 \mathrm{~mm})$ was replaced by the truncated cone mold (which height, up diameter and bottom diameter were $60 \pm 0.5$ $\mathrm{mm}, 70 \pm 0.5 \mathrm{~mm}$ and $100 \pm 0.5 \mathrm{~mm}$, respectively). The bleeding rate was measured according to USA standard "Standard Test Methods for Bleeding of Concrete" (ASTM C232/C232M-09). The cylinder mold was $108 \times 109 \mathrm{~mm}$ instead of the cylinder mold $(255 \times 280 \mathrm{~mm})$. The compressive strength of hardened mixtures was measured at 2-hour, 3-hour, 4-hour, 7-hour, 1-day, 3-day, 7-day, 28-day, 56-day and 91-day according to USA standard "Standard Test Method for Compressive Strength of Cylindrical Concrete Specimens" (ASTM C39/ C39M-14a). The size of specimen was $70.7 \times 70.7 \times 70.7 \mathrm{~mm}$.

\section{Results and Discussion}

\subsection{Flowability and Bleeding Rate}

The results of flowability and bleeding rate are shown in Figure 2 and Figure 3, respectively. It can be seen from these figures that at the same cement-to-sand $(\mathrm{C} / \mathrm{Sa})$ ratio, the flowability and bleeding rate increase with the water-to-solid (W/So) ratio from 0.25 to 0.31 , which indicates that the mixing water plays a significant role on the workability of rapid hardening CLSM. The more the mixing water used, the greater the flowability and bleeding rate are. In addition, at the same water-to-solid (W/So) ratio, the flowability and bleeding rate also 


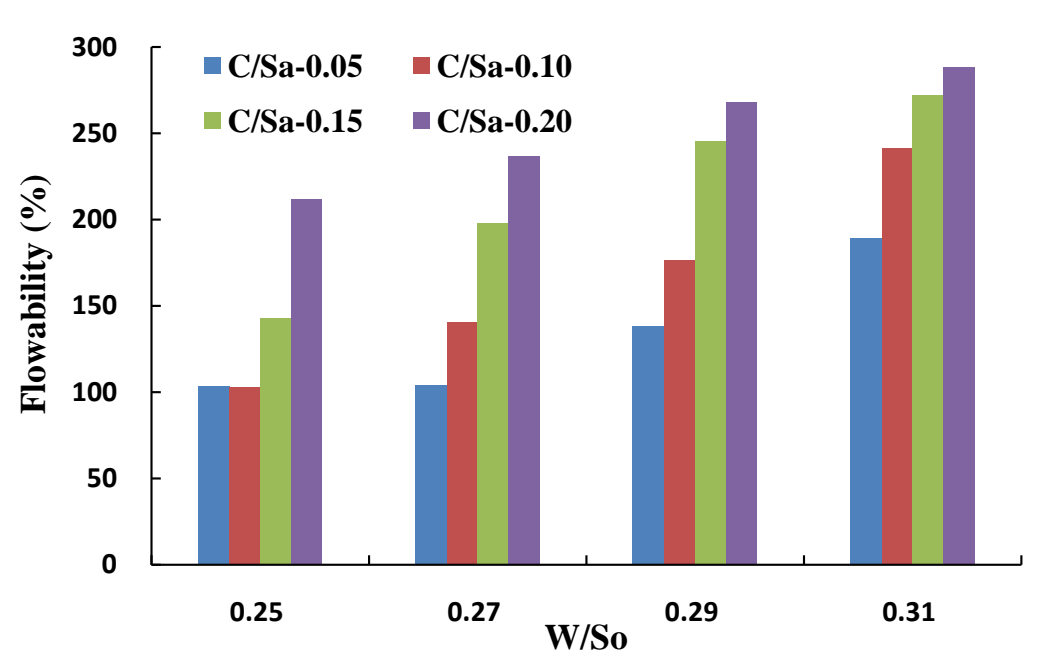

Figure 2. Flowability of fresh rapid hardening CLSM.

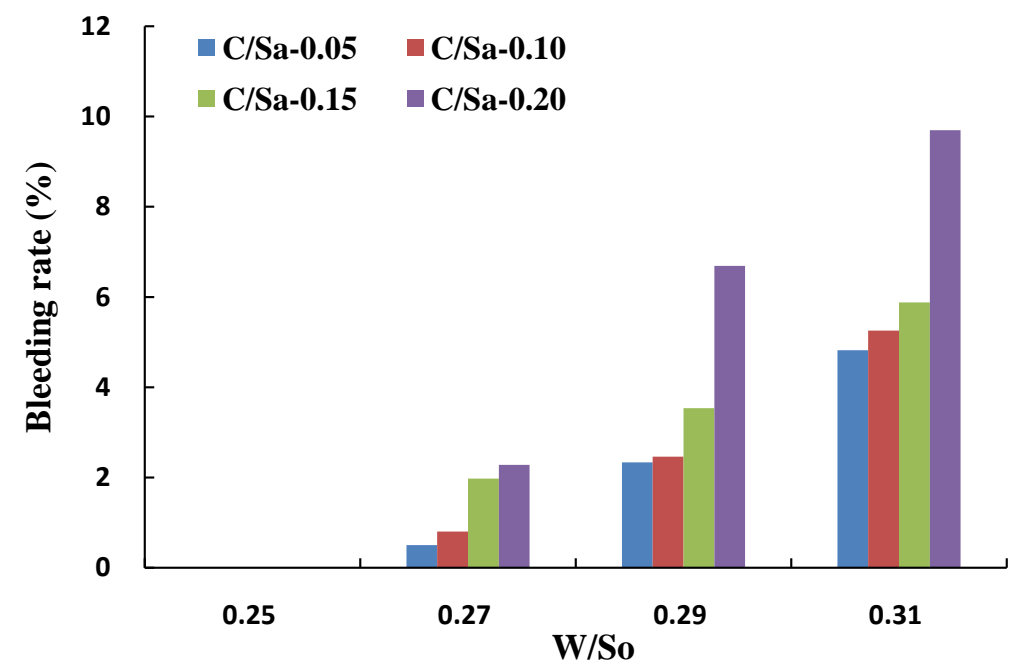

Figure 3. Bleeding rate of fresh rapid hardening CLSM.

increase with the cement-to-sand $(\mathrm{C} / \mathrm{Sa})$ ratio from 0.05 to 0.20 , which can be related to the use of water reducing agent. Although the adding percentage of water reducing agent in each mixture is fixed at $3.0 \%$ of cement by weight, an increase in the cement-to-sand $(\mathrm{C} / \mathrm{Sa})$ ratio results in more water reducing agent. So, more water reducing agent result in higher flowability and bleeding rate.

Figure 4 shows that there are best-fit straight line relationships between the flowability and bleeding rate of rapid hardening CLSM. The bleeding rate of fresh rapid hardening CLSM increases together with the increase of flowability at the same cement-to-sand $(\mathrm{C} / \mathrm{Sa})$ ratio, due to more mixing water and water reducing agent as mentioned above.

\subsection{Rapid Hardening Property}

Taking rapid hardening CLSM at the water-to-solid (W/So) ratio of 0.25 for example, Figure 5 shows that it can obtain a certain compressive strength at 2 


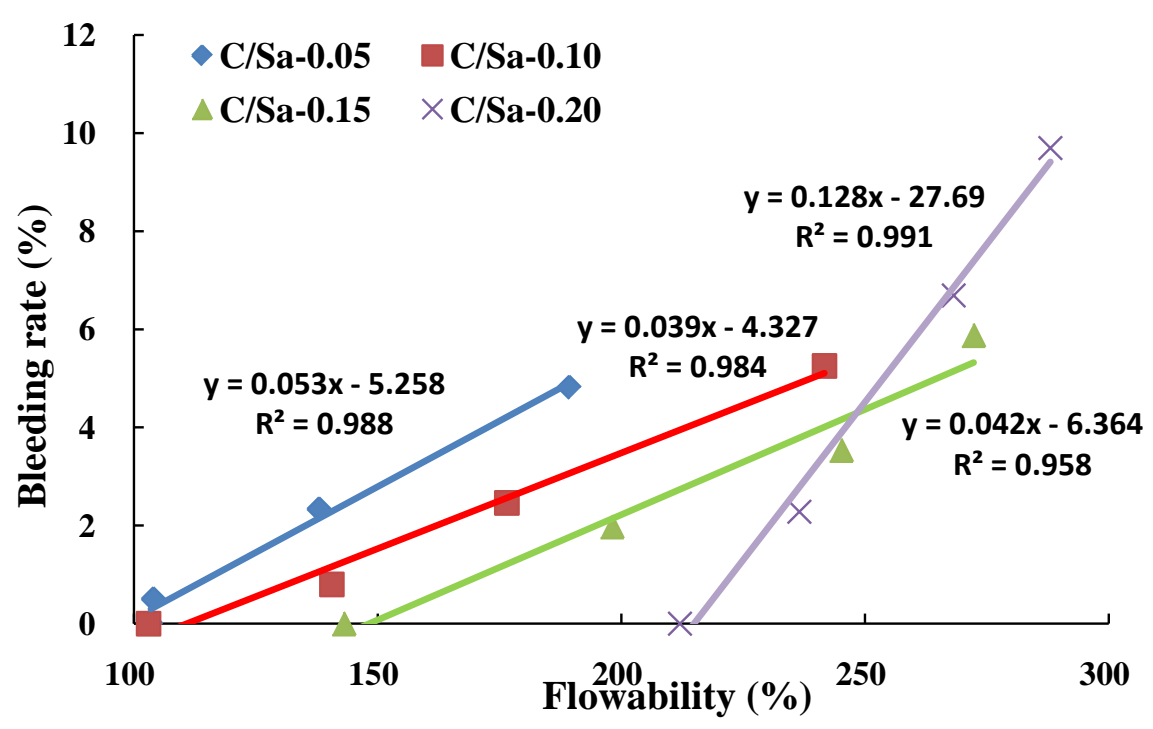

Figure 4. Relationship between flowability and bleeding rate.

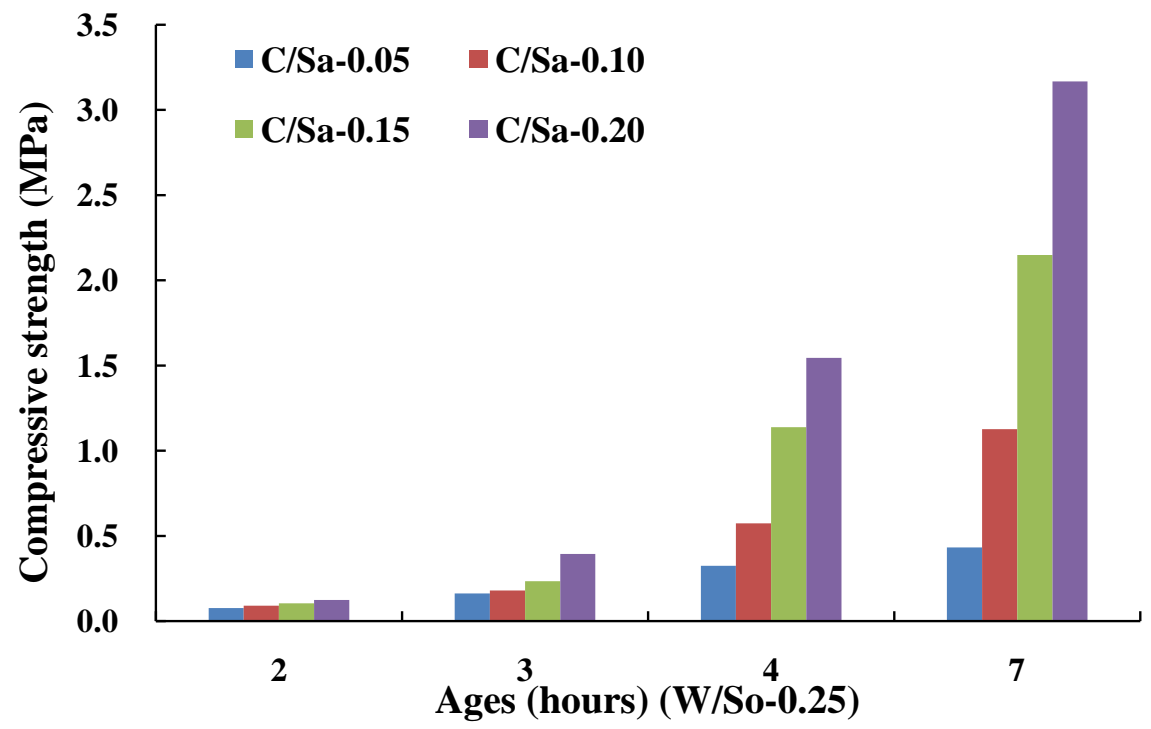

Figure 5. Rapid hardening property development of rapid hardening CLSM.

hour, which is $0.08-0.12 \mathrm{MPa}$, and 3-hour compressive strength can reach 0.16 - 0.39 MPa. These data indicate that this backfill material has a good fast-setting and rapid hardening property. Its 4 -hour compressive strength increases quickly, which is $0.32-1.54 \mathrm{MPa}$, also 7-hour compressive strength can reach $0.43-3.17$ $\mathrm{MPa}$. Test results meet the requirements of emergency backfill construction.

\subsection{Compressive Strength}

Figure 6 shows the compressive strength development of rapid hardening CLSM at different curing time when the cement-to-sand $(\mathrm{C} / \mathrm{Sa})$ ratio is $0.05(\mathrm{a}), 0.10$ (b), 0.15 (c) and 0.20 (d), respectively. At the same water-to-solid (W/So) ratio, the compressive strength increases with curing ages, and it grows quickly within 56 days, and continues to grow after 56 days, whereas the growth speed becomes 


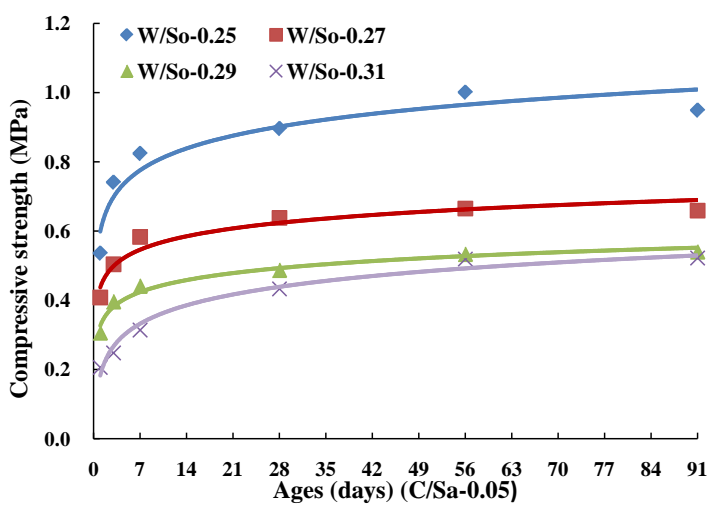

(a)

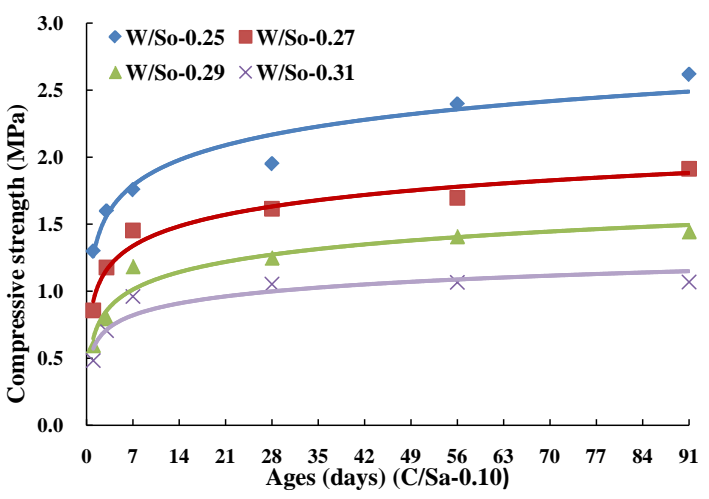

(b)

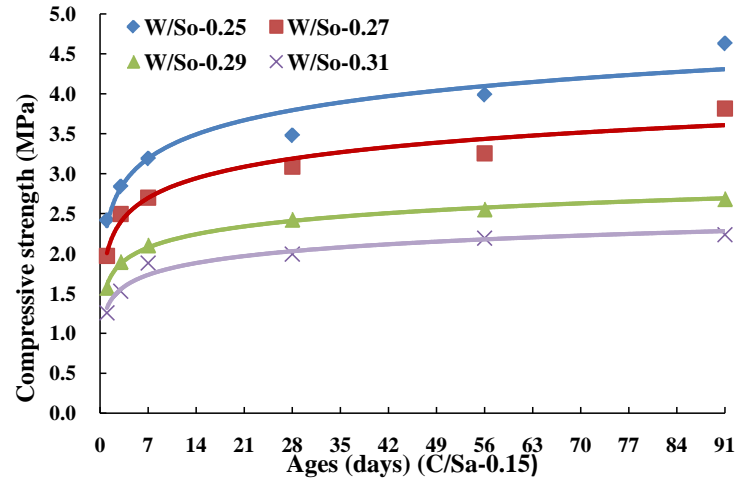

(c)

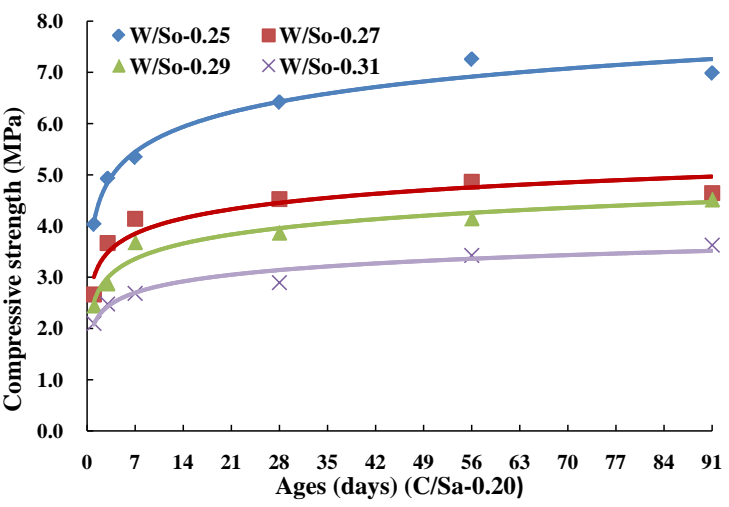

(d)

Figure 6. Compressive strength development of rapid hardening CLSM. 
slow relatively. The compressive strength at the same curing age increases with the increase of cement-to-sand $(\mathrm{C} / \mathrm{Sa})$ ratio, and decreases with the increase of water-to-solid (W/So) ratio.

Referred to the compressive strength prediction model of soil-based controlled low strength material containing stainless steel reducing slag proposed in the literature [11], a fitting model for predicting compressive strength of rapid hardening CLSM containing recycled fine aggregate from urban red brick construction waste was established.

$$
f_{c}(t)=a(t) \cdot\left(\frac{C}{S a}\right)^{b_{1}(t)} \cdot\left(\frac{W}{S o}\right)^{b_{2}(t)}
$$

where: $f_{c}(t)$ is the compressive strength at curing ages (days), C/Sa is the cementto-sand ratio, W/So is the water-to-solid ratio, and $a(t), b_{1}(t)$ and $b_{2}(t)$ are coefficients depending on curing ages (days) and calculated by the following equations:

$$
\begin{aligned}
& a(t)=0.1149 \ln (t)+0.2904 \\
& b_{1}(t)=-0.02 \ln (t)+1.4989 \\
& b_{2}(t)=0.1254 \ln (t)-3.6677
\end{aligned}
$$

Three rapid hardening CLSMs were prepared to verify the accuracy of this model. The cement-to-sand (C/Sa) ratios of R1, R2 and R3 were $0.05,0.15$ and 0.20 , respectively. And their water-to-solid (W/So) ratios were $0.29,0.27$ and 0.29 , respectively. The predicted values and measured data of compressive strength of three mixtures were shown in Figure 7. It can be seen that the predicted compressive strength has the same variation trend as their actual data, and most of predicted values match well with the measured values.

\section{Conclusions}

Rapid hardening CLSM containing recycled fine aggregate from urban red brick construction waste is environmental-friendly and low-cost compared with traditional backfill materials. The following conclusions can be summarized:

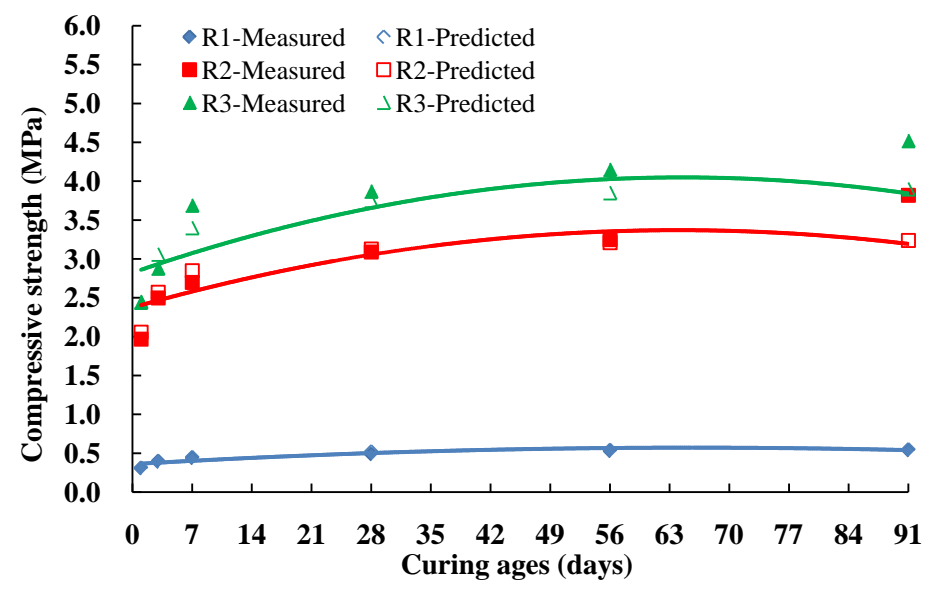

Figure 7. Comparison between test data and predicted data of compressive strength. 
1) The cement-to-sand $(\mathrm{C} / \mathrm{Sa})$ ratio and the water-to-solid (W/So) ratio are two suitable mix proportion design parameters to calculate the dosage of different materials in rapid hardening CLSM. The water-to-solid (W/So) ratio is the major indicator, which affects the workability of fresh mixture, and affects the compressive strength of hardened mixture. The cement-to-sand $(\mathrm{C} / \mathrm{Sa})$ ratio is the major indicator, which affects the compressive strength of hardened mixture.

2) The flowability of fresh mixture increases with the increase of water-tosolid (W/So) ratio, while the bleeding rate increases also with the increase of flowability. Rapid hardening CLSM needs to have the higher flow ability, whereas the higher bleeding rate has probably an adverse influence on the normal condensation and hardening of material, the internal structure and properties of hardened mixture. Therefore, how to reduce the bleeding rate under the desirable flowability is a key point of further research.

3) 2-hour compressive strength of rapid hardening CLSM is $0.08-0.12 \mathrm{MPa}$, and after 4 hours, its compressive strength increases quickly, which indicates that this new mixture can be used in either the emergency backfill engineering or some special backfill engineering projects to substitute traditional backfill materials.

4) The predicted model of compressive strength of rapid hardening CLSM is reasonably established by regression approach, in which two independent variables $(\mathrm{C} / \mathrm{Sa}$ and $\mathrm{W} / \mathrm{So})$ as well as curing ages are taken into account. However, the proposed model is based on the 1 day to 91 days compressive strength data, viz. it cannot be used to evaluate compressive strength within 1 day. The suggested formula should also be further confirmed in the future practice because it has been established based on limited data.

\section{Acknowledgements}

This research was funded by the Science and Technology Project of Beijing Municipal Commission of Transport (2016-LZJKJ-01-006), the Science and Technology Support Program of China (2014BAC07B03), and the National Natural Science Foundation of China (51278016).

\section{References}

[1] Li, J.B., Xiao, J.Z. and Sun, Z.P. (2004) Properties of Recycled Coarse Aggregate and Its Influence on Recycled Concrete (in Chinese). Journal of Building Materials, 7, 390-395.

[2] Zhou, W.J., Chen, J.L. and Lu, H.B. (2009) Research on the Green Recycled Mortar (in Chinese). Journal of Wuhan University of Technology, 31, 15-18.

[3] Li, S.D., Gao, J., Liu, R. and Zhang, H.X. (2006) Industrial Test of Construction Waste in Producing Fired Hollow Bricks (in Chinese). Wall Material Innovation \& Energy Saving in Buildings, 1, 44-46.

[4] Zhu, X.H. (2001) Utilization of Construction Waste in Producing Light Blocks (in Chinese). Block-Brick-Tile, 4, 41-42.

[5] Zhang, H., Ling, J.M. and Qian, J.S. (2011) Review on Controlled Low-Strength Materials (CLSM) (in Chinese). East China Highway, 6, 49-54. 
[6] American Concrete Institute Committee 229. (2006) Controlled Low-Strength Materials (CLSM). Farmington Hills, MI, USA.

[7] Alizadeh, V., Helwany, S., Ghorbanpoor, A. and Sobolev, K. (2014) Design and Application of Controlled Low Strength Materials as a Structural Fill. Construction and Building Materials, 53, 425-431.

[8] Farrag, K. (2011) Controlled Low-Strength Material used around Buried Pipelines. Transportation Research Record: Journal of the Transportation Research Board, 2251, 157-164. https://doi.org/10.3141/2251-16

[9] Bertola, F., Bassani, M., Canonico, F. and Bianchi, M. (2013) Long-Term Investigation into the Use of New Rapid Hardening Cement for Controlled Low-Strength Materials to be Employed in Pavement Applications. Proceedings of the 92nd Annual Meeting of Transportation Research Board of the National Academies, Washington, D.C., 12-16 January 2013, 1-16.

[10] Wei, J.J., Zhang, J.X. and Wang J.G. (2016) Properties of Flowable Backfill Materials Using Recycled Fine Aggregates of Brick and Concrete Waste (in Chinese). Journal of Civil, Architectural \& Environmental Engineering, 38, 96-103.

[11] Sheen, Y.N., Huang, L.J., Wang, H.Y. and Le, D.H. (2014) Experimental Study and Strength Formulation of Soil-based Controlled Low-Strength Material Containing Stainless Steel Reducing Slag. Construction and Building Materials, 54, 1-9

\section{Scientific Research Publishing}

\section{Submit or recommend next manuscript to SCIRP and we will provide best service for you:}

Accepting pre-submission inquiries through Email, Facebook, LinkedIn, Twitter, etc. A wide selection of journals (inclusive of 9 subjects, more than 200 journals) Providing 24-hour high-quality service User-friendly online submission system Fair and swift peer-review system Efficient typesetting and proofreading procedure Display of the result of downloads and visits, as well as the number of cited articles Maximum dissemination of your research work

Submit your manuscript at: http://papersubmission.scirp.org/ Or contactwjet@scirp.org 